Check for updates

Cite this: RSC Adv., 2017, 7, 25969

\title{
Selective removal of cationic micro-pollutants using disulfide-linked network structures $\uparrow$
}

\author{
Mehmet Sahin Atas, ${ }^{a}$ Sami Dursun, ${ }^{a}$ Hasan Akyildiz, ${ }^{a}$ Murat Citir, (D) b \\ Cafer T. Yavuz (D) ${ }^{* c}$ and Mustafa Selman Yavuz (DD *a
}

\begin{abstract}
Micropollutants are found in all water sources, even after thorough treatments that include membrane filtration. New ones emerge as complex molecules are continuously produced and discarded after used. Treatment methods and sorbent designs are mainly based on non-specific interactions and, therefore, have been elusive. Here, we developed swellable covalent organic polymers (COP) with great affinity towards micropollutants, such as textile industry dyes. Surprisingly, only cationic dyes in aqueous solution were selectively and completely removed. Studies of the COPs surfaces led to a gating capture, where negatively charged layer attracts cationic dyes and moves them inside the swollen gel through diffusive and hydrophobic interaction of the hydrocarbon fragments. Despite its larger molecular size, crystal violet has been taken the most, $13.4 \mathrm{mg} \mathrm{g}^{-1}$, surpassing all competing sorbents. The maximum adsorption capacity increased from 12.4 to $14.6 \mathrm{mg}$ and from 8.9 to $11.4 \mathrm{mg}$ when the temperature of dye solution was increased from 20 to $70{ }^{\circ} \mathrm{C}$. The results indicated that disulfide-linked COPs are attractive candidates for selectively eliminating cationic dyes from industrial wastewater due to exceptional swelling behaviour, low-cost and easy synthesis.
\end{abstract}

Received 28th April 2017

Accepted 3rd May 2017

DOI: $10.1039 / \mathrm{c} 7 \mathrm{ra0} 4775 \mathrm{~d}$

rsc.li/rsc-advances are affected by the contaminant induced inhibition of the photosynthetic activity. ${ }^{8}$

In recent years, a number of techniques were employed for the removal of organic pollutants from effluents, including precipitation, membrane filtration, coagulation, ion exchange, adsorption and chemical oxidation. ${ }^{9-15}$ Among these methods, adsorption is one of the promising techniques, ${ }^{16-19}$ mainly due to the effective procedure, operational simplicity, low cost and low energy requirements. ${ }^{1}$ The most widely used adsorbents include mesoporous silica, ${ }^{20}$ organoclays, ${ }^{21}$ powdered activated sludge, ${ }^{22}$ activated carbon, ${ }^{23}$ magnetic nanoparticles, ${ }^{24,25}$ zeolite, ${ }^{26}$ molecular sieves, ${ }^{27,28}$ activated aluminium oxide ${ }^{29}$ and porous polymers. ${ }^{30-34}$ Recently, we have shown that a fluorinated porous polymer can separate water-soluble organic molecules based on their sizes and charges. ${ }^{2}$

Network polymers have been increasingly studied for their tunable functionalities, controllable pore geometries and wide range of applications. ${ }^{35-42}$ Although conventional polymers and their derivatives, such as poly(acrylic acid) ${ }^{43}$ cellulose, ${ }^{44}$ carbonaceous materials, ${ }^{45,46}$ poly(orthocarbonate) ${ }^{47}$ microporous polymers, ${ }^{48,49}$ poly(lactic acid), ${ }^{50}$ polyaniline, ${ }^{51-53}$ were used as superabsorbents to remove oils, metal ions, toxic dyes and organic solvents from water, some of these materials were synthesized by using transition metal catalysts and sometimes at high temperatures. ${ }^{54}$ Therefore, new, low cost and effective adsorbents are always needed. One particular challenge is that high selectivity requires targeted chemistry, and such control on chemical architecture brings additional costs in material production. ${ }^{41}$
${ }^{a}$ Metallurgy and Materials Engineering Department, Selcuk University, Konya, Turkey. E-mail: selmanyavuz@gmail.com

${ }^{b}$ Materials Science and Nanotechnology Engineering, Abdullah Gül University, Melikgazi 38039, Kayseri, Turkey

${ }^{c}$ Graduate School of EEWS, Korea Advanced Institute of Science and Technology (KAIST), Daejeon, 34141 Republic of Korea.E-mail: yavuz@kaist.ac.kr

$\dagger$ Electronic supplementary information (ESI) available. See DOI: $10.1039 / \mathrm{c} 7 \mathrm{ra04775d}$ 
Covalent Organic Polymers (COPs) are highly stable and inexpensive solids ${ }^{\mathbf{4 1 , 5 5}}$ that are often made from commercially available monomers with simple chemical transformations. In this study, we used two inexpensive disulfide-linked covalent organic polymers, COP-65 and COP-66, for selective dye uptake. Surprisingly, only cationic dyes were captured and the capacities did not follow simple surface monolayer coverage. These COPs were generated through disulfide linkages $(-\mathrm{S}-\mathrm{S}-)$ by easy oxidative coupling under catalyst-free mild conditions. Adsorption and kinetics of textile dye removal from aqueous solutions were analysed with respect to the initial dye concentration, temperature, $\mathrm{pH}$ and sorbent dosage. Our findings point to significant potential for swellable polymers in effective water treatment needs.

\section{Experimental}

\section{Materials}

Trimethylolpropane tris(3-mercaptopropionate) (98\%, 3SH) and pentaerythritol tetrakis(3-mercaptopropionate) $(98 \%, 4 \mathrm{SH})$ were obtained from Sigma-Aldrich. Dimethyl sulfoxide (99.5\%, DMSO), tetrahydrofuran (98\%, THF) and methanol (98\%, $\mathrm{MeOH})$ were purchased from Merck Chemical Company. Cationic dye Rhodamine B (RB) was obtained from Alfa Aesar, Methylene Blue (MB) and Crystal Violet (CV) were purchased from Merck Chemical Company and used as received. Anionic dyes Alizarin Yellow R (AY), Methyl Orange (MO) and Orange G Sodium Salt (OG) were purchased from Alfa Aesar, SigmaAldrich and Amresco, respectively. All chemicals were used as received without any further purification.

\section{Synthesis of covalent organic polymers (COPs)}

Disulfide-linked covalent organic polymers (COPs) were reproduced through catalyst-free oxidative coupling polymerization according to our earlier method (Fig. 1). ${ }^{56}$ In a typical synthesis, trimethylolpropane tris(3-mercaptopropionate) (3SH) or pentaerythritol tetrakis(3-mercaptopropionate) $(4 \mathrm{SH})$ was added into DMSO, and the solution was heated at $80{ }^{\circ} \mathrm{C}$ for $24 \mathrm{~h}$ under vigorous stirring. The reaction mixture was cooled down to room temperature. The precipitates were centrifuged and soaked in THF for $12 \mathrm{~h}$. Washing procedure was repeated four times. Finally, a gel-like material was dried at $50{ }^{\circ} \mathrm{C}$ for $2 \mathrm{~h}$ and $100^{\circ} \mathrm{C}$ for $5 \mathrm{~h}$ under vacuum to obtain COP-65 (by using $3 \mathrm{SH}$ ) or COP-66 (by using 4SH). FTIR spectroscopy (VERTEX-70 Bruker, Germany) was used for the structural confirmations of each synthesized COPs at room temperature (Fig. S1 in the ESI $\dagger$ ). Solid-state cross polarization magic angle spinning (CP/MAS) NMR spectra were recorded on a Bruker Avance III $400 \mathrm{WB}$ NMR spectrometer (Fig. S2 in the ESI $\dagger$ ).

\section{Adsorption studies}

All the adsorption experiments were carried out in $20 \mathrm{~mL}$ glass vials. Before adsorption experiments, calibration curves for each dye, CV, MB, RB, AY, MO and OG solutions (500 $\mathrm{mg} \mathrm{L}^{-1}$ ) were prepared by using Biochrom Libra S22 model UV-Vis spectrophotometer. The dye uptake study was performed using an incubator shaker. Samples were placed in an incubator shaker (ZHWY-200B, Labwit, Shanghai, China), which was set at a speed of $150 \mathrm{rpm}$ and temperature of $30^{\circ} \mathrm{C}$.

In a typical adsorption study, $100 \mathrm{mg}$ of COPs was added to a $3 \mathrm{~mL}$ of an aqueous micropollutant solution $\left(500 \mathrm{mg} \mathrm{L}^{-1}\right)$ at room temperature. After mixing by the shaker at $200 \mathrm{rpm}$ for $24 \mathrm{~h}$, the COPs were removed from the solution and supernatant was analysed by UV-Vis. For example, the adsorbed amount of $\mathrm{CV}$ dye was calculated from the difference between the concentrations of stock CV dye solution and the supernatant CV solution by UV-Vis spectrophotometry at the wavelength of $594 \mathrm{~nm}$. Other cationic dyes $\mathrm{MB}(668 \mathrm{~nm})$ and RB (554 nm), and anionic dyes as AY (374 nm), MO (463 nm) and OG (481 nm) were analysed similarly.

\section{pH variation}

The effect of the initial $\mathrm{pH}$ on the percentage removal of $\mathrm{CV}, \mathrm{MB}$ and $\mathrm{RB}$ through adsorption onto COPs from aqueous dye solution was studied. In that order, the experiments were conducted at various $\mathrm{pH}$ values, ranging from 2.0 to 10.0 with a $500 \mathrm{mg} \mathrm{L}^{-1}$ initial dye concentration and $100 \mathrm{mg}$ of COPs (adsorbent) at room temperature for $24 \mathrm{~h}$. The $\mathrm{pH}$ was adjusted with $0.1 \mathrm{M}$ hydrochloric acid $(\mathrm{HCl})$ or $0.1 \mathrm{M}$ sodium hydroxide $(\mathrm{NaOH})$ by using a $\mathrm{pH}$ meter.

\section{Contact time effect}

A mixture of aqueous initial CV dye concentrations of $500 \mathrm{mg}$ $\mathrm{L}^{-1}$ and $100 \mathrm{mg}$ of COPs (adsorbent) was shaken with an incubator shaker at $200 \mathrm{rpm}$ for $5 \mathrm{~h}$ equilibrium time at room temperature. Every $30 \mathrm{~min}$, a sample was taken for UV-Vis analysis.

\section{Temperature}

The effect of the temperature for the removal of CV by using COPs was studied at different temperatures, namely, 25, 40, 55, 70 and $90{ }^{\circ} \mathrm{C}$. Again, the experiments were performed with a solution containing an aqueous dye solution (concentration of $500 \mathrm{mg} \mathrm{L}^{-1}$ ) and $100 \mathrm{mg}$ of COPs (adsorbent) using a incubator shaker at $200 \mathrm{rpm}$ for $24 \mathrm{~h}$ equilibrium time.

\section{Dye concentration}

The effect of the contact time for the removal of CV by using COPs was studied at different dye concentration such as, 100, $200,300,400$ and $500 \mathrm{mg} \mathrm{L}^{-1}$ for $5 \mathrm{~h}$ equilibrium time under the same conditions as the temperature variation study.

\section{Desorption and recyclability}

To evaluate the possibility of regeneration of the dye-saturated adsorbent, desorption experiments were carried out using tetrahydrofuran/water (50/50) solution in an ultrasonic generator. $100 \mathrm{mg}$ COPs (adsorbents) were added to $5 \mathrm{~mL}$ of dye solutions and the mixture was shaken on a rotary shaker at $200 \mathrm{rpm}$ for $24 \mathrm{~h}$. The initial dye concentration was $500 \mathrm{mg} \mathrm{L}^{-1}$. At the end of the adsorption period, the dye-adsorbed COPs adsorbents were soaked into $3 \mathrm{~mL}$ tetrahydrofuran for 
<smiles>CCC(COC(=O)CCS)(COC(=O)CCSS)COC(=O)CCSSSCCC(=O)OCC(CC)(COC(=O)CCS)COC(=O)CCSSC</smiles><smiles>O=C(CCS)OCC(COC(=O)CCS)(COC(=O)CCS)COC(=O)CCS</smiles>

4SH

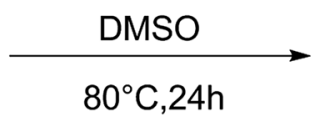

Fig. 1 Schematic illustration for one pot, open air and easy synthesis of
propionate) and pentaerythritol tetrakis(3-mercaptopropionate) in DMSO.

desorption process. The suspensions were shaken on a rotary shaker at $200 \mathrm{rpm}$ for $24 \mathrm{~h}$. Then the supernatant solutions were analysed by using UV-Vis spectrometry.

\section{Characterisation}

In order to evaluate the porosity of COPs, $\mathrm{N}_{2}$ adsorption isotherms were obtained with a Micromeritics Tristar II 3020 accelerated surface area and porosimetry analyser at $77 \mathrm{~K}$, after the samples were degassed at $150{ }^{\circ} \mathrm{C}$ for $5 \mathrm{~h}$ under vacuum prior to the measurements. The adsorption desorption isotherms were obtained to give BET $\left(P / P_{\mathrm{o}}=0.01-0.25\right)$ and Langmuir $\left(P / P_{\mathrm{o}}=\right.$ $0.1-0.35$ ) surface areas. The UV-Vis spectra from $190-900 \mathrm{~nm}$ were recorded using a Biochrom Libra S22 spectrometer using quartz cuvettes. Measurements of $\mathrm{pH}$ were obtained using an Orion Research model SA250 digital $\mathrm{pH}$ meter. Zeta potential determinations of COP-65 and COP-66 were performed in aqueous 10 $\mathrm{mM} \mathrm{NaCl}$ solutions by using Nano ZS, Malvern Instruments.

\section{Results and discussion}

The hydrophobic, aprotic behaviour of COP-65 and COP-66 led us to investigate adsorbent characteristics in removal of contaminants with complex organic molecule nature. ${ }^{56}$ Due to the easy detection and the industrial relevance, we chose common textile dyes to be screened for removal activity. We, therefore, classified the target dyes in two groups: (1) anionic, and (2) cationic. Three dyes for each group were selected:
Methyl Orange (MO), Alizarin Yellow R (AY) and Orange G Sodium Salt (OG) as anionic dyes and Crystal Violet (CV), Methylene Blue (MB) and Rhodamine B (RB) as cationic (Fig. 2). For all adsorption experiments, $100 \mathrm{mg}$ of sorbent was treated with $3 \mathrm{~mL}$ aqueous solution ( $500 \mathrm{mg} \mathrm{L}^{-1}$ ) of the selected dye.

The micropollutant dye molecules have varying sizes as well. We have recently shown that a rigid microporous polymer (COP99) can do both size and charge dependent separation. ${ }^{2}$ Here, however, the network is made up of purely aliphatic monomers and prone to swelling with no initial porosity. We anticipate a different mechanism, where guest molecules need to penetrate by expanding the network branches.

Interestingly, both COPs showed a selective uptake towards cationic dyes (Fig. 3). CV was the most captured dye molecule with capacities reaching up to $13.4 \mathrm{mg} \mathrm{g}^{-1}$ (with COP-65). RB uptake reached $10.9 \mathrm{mg} \mathrm{g}^{-1}$ and MB has a maximum of $9.5 \mathrm{mg}$ $\mathrm{g}^{-1}$ loading. However, the uptake of anionic dyes (AY, MO and OG) by both COPs was negligible. The adsorption capacities of anionic dyes were $0.425 \mathrm{mg} \mathrm{g}^{-1}$ (AY), $0.575 \mathrm{mg} \mathrm{g}^{-1}$ (MO) and $0.325 \mathrm{mg} \mathrm{g}^{-1}$ (OG) by COP-65; and $0.337 \mathrm{mg} \mathrm{g}^{-1}$ (AY), $0.445 \mathrm{mg}$ $\mathrm{g}^{-1}$ (MO) and $0.267 \mathrm{mg} \mathrm{g}^{-1}$ (OG) by COP-66.

The high capture capacities for Crystal Violet (CV) allowed us to compare our results with that of others, surpassing all of the other low cost literature examples (Table 1). ${ }^{57-62}$ These values suggest that the inexpensive COPs have great potential in selective cationic dye removal from aqueous solution. In that, COPs behave uniquely and can serve as extractors from aqueous 
(a)<smiles>CN(C)c1ccc(N=Nc2ccc(S(=O)(=O)O[Na])cc2)cc1</smiles>

Methyl Orange (MO)<smiles>CCCCOCCOCCOC(=O)c1cc(N=Nc2ccc([N+](=O)[O-])cc2)ccc1O</smiles><smiles>O=S(=O)(O)c1cc(O)c2c(N=Nc3ccccc3)c(S(=O)(=O)O)ccc2c1</smiles>

Alizarin Yellow (AY)<smiles>CN(C)c1ccc(C(=C2C=CC(=[N+](C)C)C=C2)c2ccc(N(C)C)cc2)cc1</smiles>

Crystal Violet (CV)<smiles>CN(C)c1ccc2nc3ccc(=[N+](C)C)cc-3sc2c1</smiles>

Methylene Blue (MB)<smiles>CCN(CC)c1ccc2c(-c3ccccc3C(=O)O)c3ccc(=[N+](CC)CCl)cc-3oc2c1</smiles>

Rhodamine B (RB)

Fig. 2 Chemical structures of the micro-pollutants; (a) anionic dyes: Alizarin Yellow (AY), Methyl Orange (MO) and Orange G (OG); (b) cationic dyes: Methylene Blue (MB), Crystal Violet (CV) and Rhodamine B (RB).

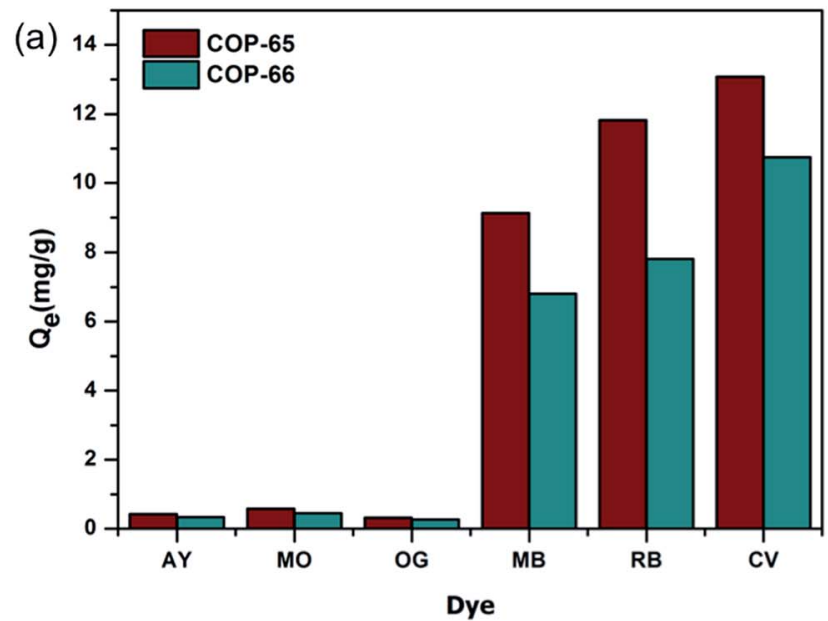

(b)

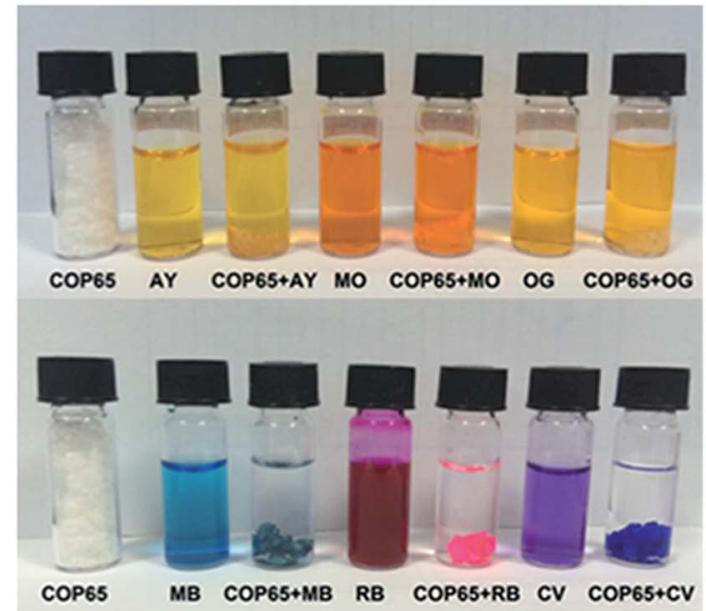

Fig. 3 (a) Adsorption capacities of COP-65 and COP-66 for six common anionic and cationic dyes, (b) digital pictures of anionic and cationic dye uptake experiment (before and after 24 h) by COP- 65 . 
Table 1 Comparison between the adsorption capacities of selective adsorbents towards Crystal Violet (CV)

\begin{tabular}{lcl}
\hline Adsorbents & $\begin{array}{l}\text { Adsorption capacity } \\
\left(\mathrm{mg} \mathrm{g}^{-1}\right)\end{array}$ & References \\
\hline Calotropis procera leaf & 4.14 & 57 \\
Jalshakti@ polymer & 12.9 & 58 \\
Sugarcane dust & 3.8 & 59 \\
Neem sawdust & 3.8 & 60 \\
Coir pith & 2.56 & 61 \\
Sugarcane fiber & 10.44 & 62 \\
COPs & $\mathbf{1 3 . 4}$ & This work
\end{tabular}

medium. This, in contrast to well known all-purpose sorbents like activated carbons, is quite different and only recently been explored. ${ }^{2}$

In order to understand why cationic dyes were taken up selectively, we measured surface charges of both COP structures. By using zeta potential readings, the surface charges of COP-65 and COP-66 were measured as $-14.6 \mathrm{mV}$ and $-8.53 \mathrm{mV}$, respectively. Negative values generally correspond to the anionic species and electronegative atoms with lone pairs. We suspect that the network building by a single monomer with thiol ends provides high thiol coverage of the surface, hence lone pairs. Deprotonation of the thiols also generate anionic sulphides and perhaps sulfonates from the oxidative coupling reaction. Ester groups on the branches of the network polymers also contribute to the electron donating nature of the surface.

The surface charges explain the favourable interaction, but our findings indicate that a swelling behaviour is mainly responsible for the selective uptake. Despite the larger hydrodynamic molecular size of the $\mathrm{CV}$, it is adsorbed the most. This leads to a conviction that uptake is not only due to surface coverage of the dye molecules. Taking all these possibilities, we suggest a "gating approach" where surface charges form an electrostatic barrier for rejection of similar charges. Then the hydrophobic interior is swollen by the interaction of hydrocarbon backbone of the dye molecules. A similar mechanism was observed when linear or branched hydrocarbons were selectively separated on a metal-organic framework (MOF), $\mathrm{Fe}_{2}(\mathrm{BDP})_{3}{ }^{63}$ Most recently, using analogous concepts, Eddaoudi and co-workers showed a very difficult separation of propylene from propane by tailor-made MOF structure, KAUST-7. ${ }^{64}$

Surface negative charge and the possibility of the deprotonation prompted us to study in detail how the surface behaves. We, therefore, carried out $\mathrm{pH}$ effect on the uptake capacities by both network polymers (Fig. 4). It is imperative that at lower $\mathrm{pH}$ values, a less negative surface is present, leading to a lower uptake of cations. The experiments were conducted at various $\mathrm{pH}$ values (ranging from 2.0 to 10.0) with a $500 \mathrm{mg} \mathrm{L}^{-1}$ initial dye concentration and $100 \mathrm{mg}$ of COP-65 and COP-66 (adsorbents) at room temperature for a day. The $\mathrm{pH}$ was adjusted by adding either $\mathrm{HCl}$ or $\mathrm{NaOH}$. The results indicate when the $\mathrm{pH}$ was changed from 2.0 to higher values up to 8.0, the amount of cationic dyes adsorbed by COP-65 and COP-66 as shown in Fig. 4a and b, respectively. At lower $\mathrm{pH}$ values, the hydrogen ion $\left(\mathrm{H}^{+}\right)$ion concentration in the aqueous system is higher, which makes the surface of COPs less negatively charged due to protonation..$^{22}$ The $\mathrm{pH}$ of the aqueous solution is above 7 , more negatively charged surfaces of both COPs are formed due to the excess hydroxide ions $\left(\mathrm{OH}^{-}\right)$. As the surfaces of COP-65 and COP-66 become negatively charged at $\mathrm{pH} 8$, there is significant electrostatic attraction between the negatively charged surface of COPs and the cationic dye molecules, which leads to a maximum dye adsorption. However, above $\mathrm{pH} 8$, the hydroxide ions are in competition with the sorbent to combine with cationic species, which lead to lower dye adsorptions by COPs due to the lack of substrate availability. ${ }^{22}$

In order to study the kinetics, we analysed the adsorption of Crystal Violet (CV) with respect to contact time and temperature (Fig. 5). The rate of CV sorption was determined in varying time intervals by mixing $500 \mathrm{mg} \mathrm{L}^{-1}$ of aqueous CV solution with $100 \mathrm{mg}$ of COP-65 or COP-66. Just after the addition of COP-65 or COP-66, the dye adsorption started immediately. The adsorption was increased sharply within $30 \mathrm{~min}$ and attained equilibrium after $2 \mathrm{~h}$ (Fig. $5 \mathrm{a}$ ). There is no significant increase in removal of CV dye after $2 \mathrm{~h}$ contact time.

Effect of temperature on the adsorption of CV by COP- 65 and COP-66 at equilibrium was investigated at five different temperatures: $25,40,55,70$ and $90{ }^{\circ} \mathrm{C}$ (Fig. 5b). We observed that the amount of adsorbed CV by COP-65 and COP-66 increased from 12.4 to $14.6 \mathrm{mg} \mathrm{g}^{-1}$ and from 8.9 to $11.4 \mathrm{mg}$ $\mathrm{g}^{-1}$, respectively, as the temperature was increased from 25 to $70{ }^{\circ} \mathrm{C}$. The enhanced adsorption at higher temperatures could be a result of an increase in the mobility of the dye molecules (higher diffusion rate) and an easier swelling within COPs at higher temperatures, which could enable the dye molecules to penetrate further inside.$^{65}$ On the other hand, we found no significant change in the CV dye adsorption efficiency after $70{ }^{\circ} \mathrm{C}$, as it nears to the boiling point of water.

We also studied the dose of the dye molecules in adsorption capacities. Fig. 6a shows the adsorption capacity of COP-65 against the contact time for varying initial concentrations $\left(100,200,300,400\right.$ and $\left.500 \mathrm{mg} \mathrm{L}^{-1}\right)$ of the Crystal Violet (CV). A fast adsorption was observed for all concentrations during the first $15 \mathrm{~min}$ due to the available surface area of the COPs for the adsorption of CV. Higher CV dye concentration led to an increase in the adsorption capacity of COP-65 due to the driving force of the concentration gradient. The amounts of dye (mg $\left.\mathrm{g}^{-1}\right)$ adsorbed on the COPs $\left(Q_{\mathrm{e}}\right)$ increased from 4.516 to $11.238 \mathrm{mg} \mathrm{g}^{-1}$ when the initial dye concentration changes from 100 to $500 \mathrm{mg} \mathrm{L}^{-1}$. Equilibrium of dye adsorption capacity was attained for all dye concentrations after $4 \mathrm{~h}$.

Recyclability of the sorbents is ultimately important for any commercial feasibility. The COP-65 was tested in terms of its reusability for three consecutive cycles. $100 \mathrm{mg}$ of COP-65 was mixed into the $500 \mathrm{mg} \mathrm{L}^{-1}$ of $\mathrm{CV}$ solution. The desorption of almost all adsorbed CV was achieved by treating with THF (a widely available industrial solvent) for $6 \mathrm{~h}$ (Fig. 6b). COP-65 showed $94.4 \%$ adsorption of $\mathrm{CV}$ in the second cycle. ${ }^{56}$ Thereafter, the adsorbent showed slight decline in its performance, both in adsorption as well as desorption. The use of the same COP-65 in the third cycle showed $93.1 \%$ dye adsorption. We suspect that the remaining adsorbed dye molecules lead to 

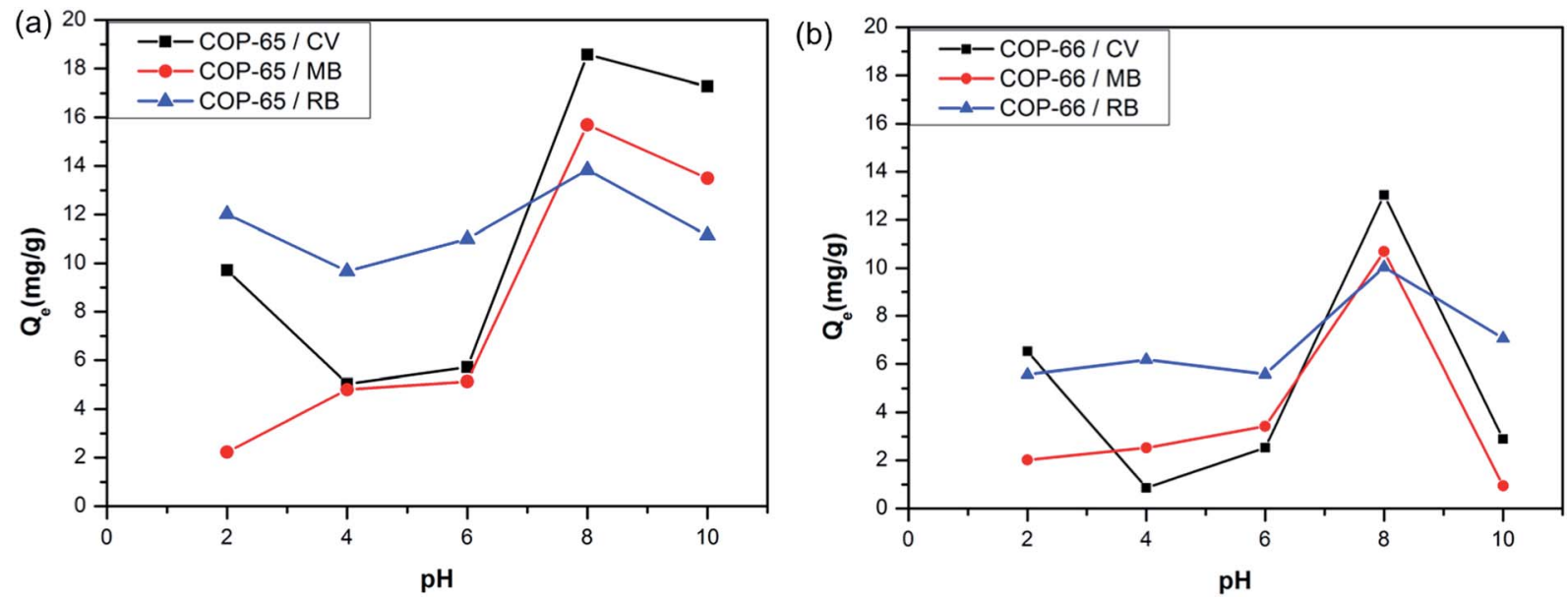

Fig. 4 Adsorption performance of cationic dyes by (a) COP-65 (b) COP-66 in varying pH conditions.
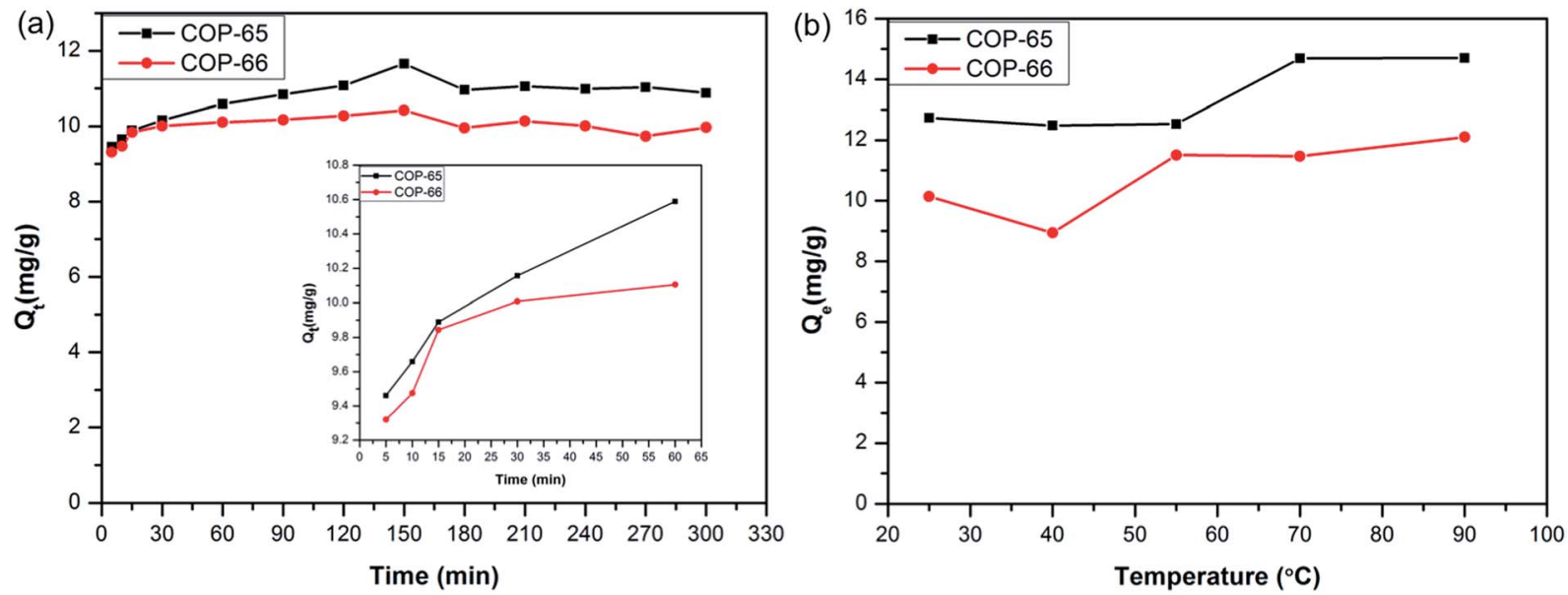

Fig. 5 Effects of (a) contact time (inset shows the first hour) and (b) temperature on adsorption capacity of Crystal Violet (CV) on COP-65 and COP-66.

(a)

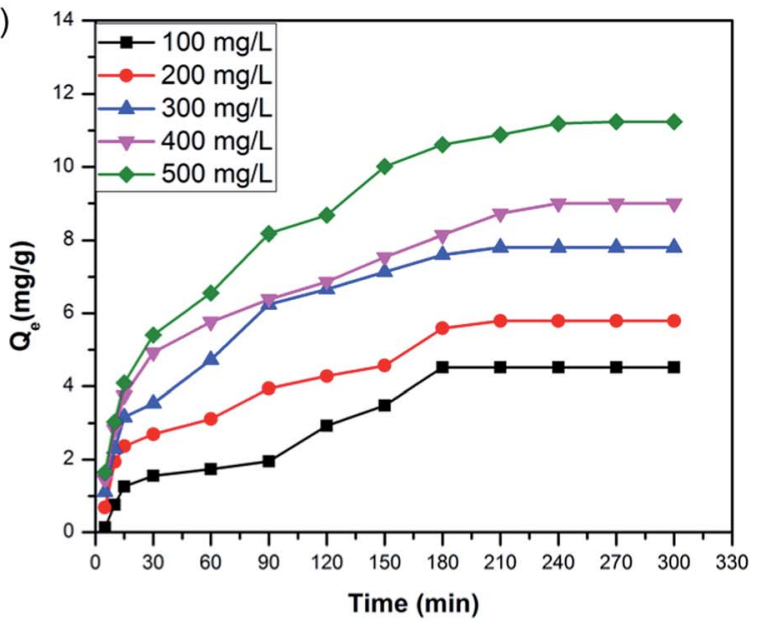

(b)

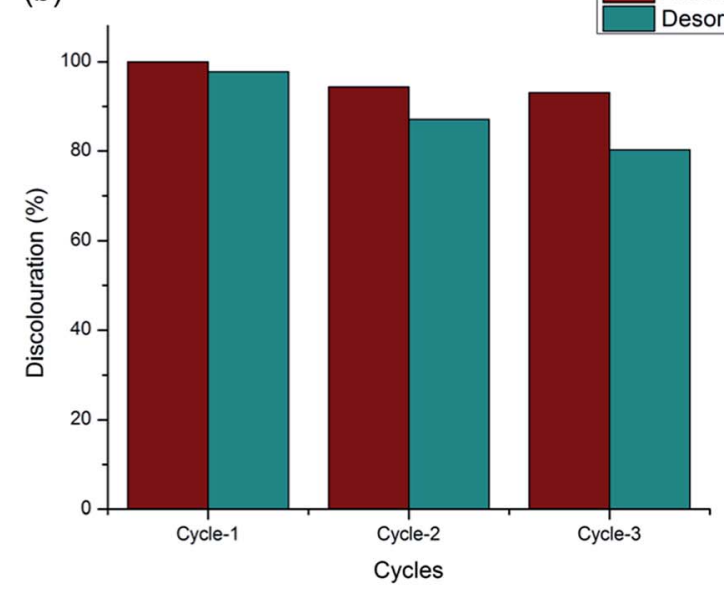

Fig. 6 (a) Effect of contact time on adsorption capacity of COP-65 with different concentrations of Crystal Violet (CV), (b) recycling experiment of COP-65 for the adsorption and desorption of CV $\left(500 \mathrm{mg} \mathrm{L}^{-1}\right)$. 
(a)

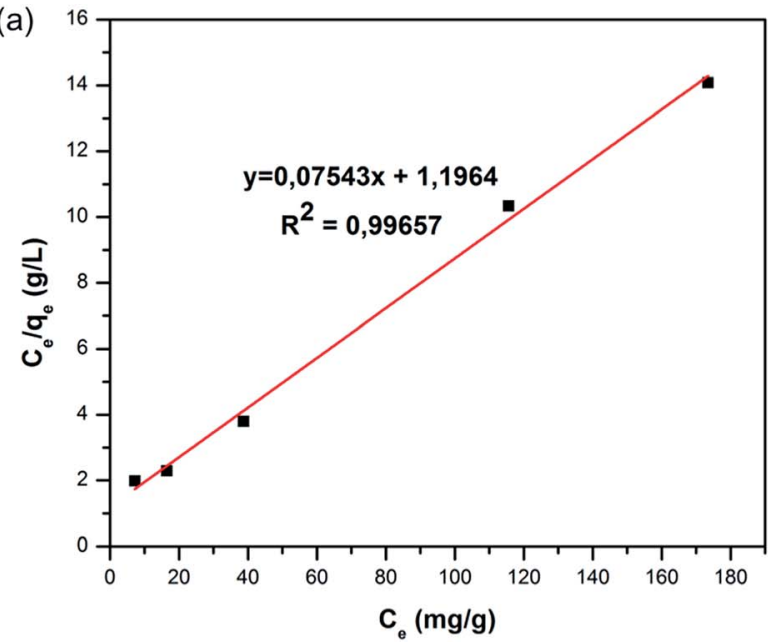

(b)

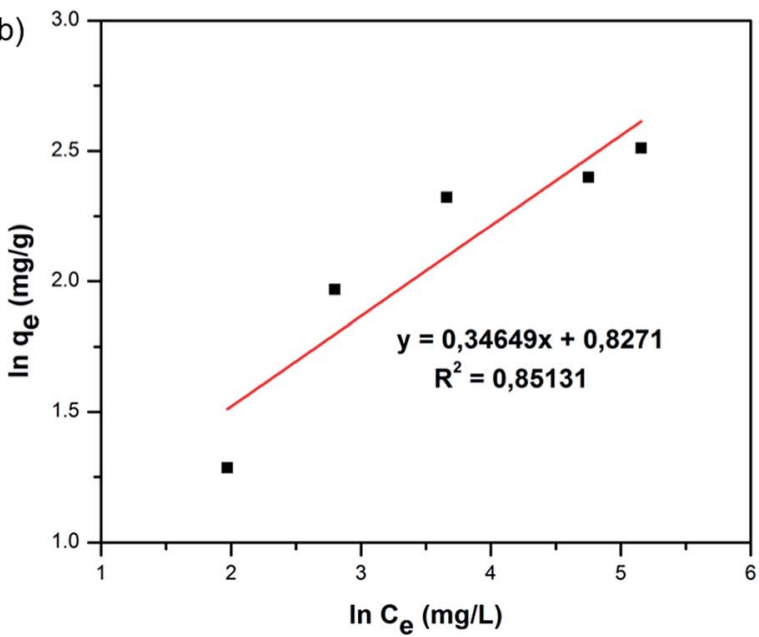

Fig. 7 The linear fittings for (a) Langmuir and (b) Freundlich adsorption isotherms for the sorption of Crystal Violet (CV) by COP-65.

decrease in both uptake and recovery of CV. Since the adsorption is purely physisorptive, mechanical or sonochemical approaches could extract all trapped molecules. Our studies are underway in that direction.

The equilibrium adsorption isotherm plays an important role in predictive modelling for design and optimization of adsorption systems. ${ }^{66}$ In order to describe the relationship between the amount of dye adsorbed and its equilibrium concentration in solution, we used two of the most commonly used models, Langmuir and Freundlich isotherms. Langmuir isotherm theory is based upon the assumption of monolayer adsorption on a homogeneous adsorbent. ${ }^{67,68}$ The linear form of the Langmuir isotherm model can be written by using the equation below:

$$
\frac{C_{\mathrm{e}}}{q_{\mathrm{e}}}=\frac{C_{\mathrm{e}}}{q_{\mathrm{m}}}+\frac{1}{K_{\mathrm{L}} q_{\mathrm{m}}}
$$

where $C_{\mathrm{e}}\left(\mathrm{mg} \mathrm{L}^{-1}\right)$ is equilibrium concentration of dye in solution, $q_{\mathrm{m}}\left(\mathrm{mg} \mathrm{g}^{-1}\right)$ is the maximum amount of dye per unit weight of adsorbent, $q_{\mathrm{e}}\left(\mathrm{mg} \mathrm{g}^{-1}\right)$ is the amount of $\mathrm{CV}$ adsorbed at equilibrium, $K_{\mathrm{L}}\left(\mathrm{L} \mathrm{mg}^{-1}\right)$ is the Langmuir equilibrium adsorption constant related to the affinity of binding sites. The linear form of the Freundlich isotherm model was also used to describe the equilibrium data by the following equation:

$$
\ln q_{\mathrm{e}}=\ln K_{\mathrm{F}}+\frac{1}{n} \ln C_{\mathrm{e}}
$$

where $K_{\mathrm{F}}\left(\mathrm{L} \mathrm{mg}^{-1}\right)$ is Freundlich constant related to adsorption intensity, $1 / n$ is the order of adsorption constant which

Table 2 The Langmuir and Freundlich isotherms model constants for the sorption of crystal violet from aqueous solution by COP- 65

\begin{tabular}{lllllll}
\hline Langmuir & & & \multicolumn{2}{l}{ Freundlich } \\
\cline { 1 - 1 } $\begin{array}{lllllll}q_{\mathrm{m}} \\
\left(\mathrm{mg} \mathrm{g}^{-1}\right)\end{array}$ & $\begin{array}{l}K_{\mathrm{L}} \\
\left(\mathrm{L} \mathrm{mg}^{-1}\right)\end{array}$ & $R^{2}$ & & $\begin{array}{l}K_{\mathrm{F}} \\
\left(\mathrm{L} \mathrm{mg}^{-1}\right)\end{array}$ & $n$ & $R^{2}$ \\
\hline 13.245 & 0.063 & 0.99657 & 2.287 & 2.886 & 0.85131
\end{tabular}

indicates whether the nature of adsorption is favourable or not. A relatively high value of $n(n>1)$ indicates good adsorption intensity over the entire range of concentrations being studied.

Linear plots of $C_{\mathrm{e}} / q_{\mathrm{e}}$ versus $C_{\mathrm{e}}$ and $\ln q_{\mathrm{e}}$ versus $\ln C_{\mathrm{e}}$ are shown in Fig. 7. The values of $q_{\mathrm{m}}$ and $K_{\mathrm{L}}$ in the Langmuir isotherm model and the values of $K_{\mathrm{F}}$ and $n$ in the Freundlich isotherm model are presented in Table 2 . These results indicate that the CV dye in the aqueous solution is favourably adsorbed by the COP-65. The $R^{2}$ value with respect to sorption of $\mathrm{CV}$ for Langmuir isotherm model was noted to be 0.99657 , which was 0.85131 for Freundlich isotherm model. It could be concluded from these observations that the adsorption of $\mathrm{CV}$ by using COP-65 was better defined by the Langmuir than Freundlich isotherm model.

\section{Conclusions}

We have demonstrated selective cationic micropollutant (in this case textile dyes) removal from aqueous solutions by using covalent organic polymers (COPs) that were synthesized by catalyst-free oxidative coupling polymerization of tetravalent or trivalent aliphatic thiols. COP-65 and COP-66 were obtained from commercially available and inexpensive monomers, and the resultant swellable insoluble networks exhibited unique uptake behaviour for three different cationic dyes. Interestingly, only cationic dyes were taken in favourably by these sorbents. Crystal Violet (CV) was captured the highest, despite its larger hydrodynamic structure. As temperature, initial dye concentrations or contact time increases, higher adsorption of $\mathrm{CV}$ was observed. The experimental data correlated well by the Langmuir adsorption isotherm compared to Freundlich ones. The present study concludes that the disulfide COPs could be employed effectively as affordable adsorbents for the removal of cationic micropollutants from aqueous media. In the future, new and improved polymer networks will be evaluated for a variety of potential applications and investigated with respect 
to different parameters that include a multivariate study of experimental design and chemometrics.

\section{Acknowledgements}

This study was carried out as a Master thesis by Mehmet Sahin Atas at the Graduate School of Natural and Applied Science at Selcuk University, Konya, Turkey. Support for this work is provided by the Scientific Research Foundation (BAP) of Selçuk University, Scientific and Technological Research Council of Turkey (TUBITAK MAG) (Project Number 214M232) and Academic Staff Training Program (ÖYP) (Project Number 2015ÖYP-128), which authors gratefully acknowledge. C. T. Y. thanks for the support from National Research Foundation (NRF) of Korea, No: NRF-2016R1A2B4011027.

\section{References}

1 A. Alsbaiee, B. J. Smith, L. Xiao, Y. Ling, D. E. Helbling and W. R. Dichtel, Nature, 2016, 529, 190-194.

2 J. Byun, H. A. Patel, D. Thirion and C. T. Yavuz, Nat. Commun., 2016, 7, 13377.

3 B. Miccoli, V. Cauda, A. Bonanno, A. Sanginario, K. Bejtka, F. Bella, M. Fontana and D. Demarchi, Sci. Rep., 2016, 6, 29763.

4 M. Ibáñez, V. Borova, C. Boix, R. Aalizadeh, R. Bade, N. S. Thomaidis and F. Hernández, J. Hazard. Mater., 2017, 323, 26-35.

5 G. Crini, Bioresour. Technol., 2006, 97, 1061-1085.

6 R. Gong, M. Li, C. Yang, Y. Sun and J. Chen, J. Hazard. Mater., 2005, 121, 247-250.

7 F.-C. Wu and R.-L. Tseng, J. Hazard. Mater., 2008, 152, 12561267.

8 C. J. Madadrang, H. Y. Kim, G. Gao, N. Wang, J. Zhu, H. Feng, M. Gorring, M. L. Kasner and S. Hou, ACS Appl. Mater. Interfaces, 2012, 4, 1186-1193.

9 M.-S. Chiou and G.-S. Chuang, Chemosphere, 2006, 62, 731-740.

10 J.-L. Gong, B. Wang, G.-M. Zeng, C.-P. Yang, C.-G. Niu, Q.-Y. Niu, W.-J. Zhou and Y. Liang, J. Hazard. Mater., 2009, 164, 1517-1522.

11 T.-H. Kim, C. Park and S. Kim, J. Cleaner Prod., 2005, 13, 779786.

12 R. J. Stephenson and S. J. Duff, Water Res., 1996, 30, 781-792.

13 D. P. Mesquita, A. L. Amaral and E. C. Ferreira, Chem. Eng. J., 2016, 285, 349-357.

14 F. Bella, D. Pugliese, J. R. Nair, A. Sacco, S. Bianco, C. Gerbaldi, C. Barolo and R. Bongiovanni, Phys. Chem. Chem. Phys., 2013, 15, 3706-3711.

15 F. Bella, M. Imperiyka and A. Ahmad, J. Photochem. Photobiol., A, 2014, 289, 73-80.

16 V. Gupta, J. Environ. Manage., 2009, 90, 2313-2342.

17 A. Gürses, Ç. Doğar, M. Yalçın, M. Açıkyıldız, R. Bayrak and S. Karaca, J. Hazard. Mater., 2006, 131, 217-228.

18 J. Y. Song, B. N. Bhadra and S. H. Jhung, Microporous Mesoporous Mater., 2017, 243, 221-228.

19 R. K. Motkuri, H. V. R. Annapureddy, M. Vijaykumar, H. T. Schaef, P. F. Martin, B. P. McGrail, L. X. Dang,
R. Krishna and P. K. Thallapally, Nat. Commun., 2014, 5, 4368.

20 K. Y. Ho, G. McKay and K. L. Yeung, Langmuir, 2003, 19, 3019-3024.

21 H. A. Patel, H. C. Bajaj and R. V. Jasra, Ind. Eng. Chem. Res., 2008, 48, 1051-1058.

22 M. Doğan, M. Alkan, A. Türkyilmaz and Y. Özdemir, J. Hazard. Mater., 2004, 109, 141-148.

23 Y. Sharma, U. S. Upadhyay and F. Gode, J. Appl. Sci. Environ. Sanit., 2009, 4, 21-24.

24 C. Junyong, H. Yongmei, L. Yan and G. Jiajia, $R S C A d v ., 2013$, 3, 7254-7258.

25 D. Das, J. Plazas-Tuttle, I. V. Sabaraya, S. S. Jain, T. SaboAttwood and N. B. Saleh, Environ. Sci.: Nano, 2017, 4, 60-68.

26 M. R. Delgado and C. O. Arean, Energy, 2011, 36, 5286-5291.

27 H. Huang, C. Yang, H. Zhang and M. Liu, Microporous Mesoporous Mater., 2008, 111, 254-259.

28 D. Lozano-Castello, J. Alcaniz-Monge, D. Cazorla-Amoros, A. Linares-Solano, W. Zhu, F. Kapteijn and J. Moulijn, Carbon, 2005, 43, 1643-1651.

29 A. Genz, A. Kornmüller and M. Jekel, Water Res., 2004, 38, 3523-3530.

30 S. Debnath, A. Shome, S. Dutta and P. K. Das, Chem.-Eur. J., 2008, 14, 6870-6881.

31 B. Pan, B. Pan, W. Zhang, L. Lv, Q. Zhang and S. Zheng, Chem. Eng. J., 2009, 151, 19-29.

32 Y. Zhang, S. Wei, Y. He, F. Nawaz, S. Liu, H. Zhang and F.-S. Xiao, J. Mater. Chem., 2010, 20, 4609-4614.

33 B. Ashourirad, P. Arab, T. Islamoglu, K. A. Cychosz, M. Thommes and H. M. El-Kaderi, J. Mater. Chem. A, 2016, 4, 14693-14702.

34 X. Zhu, S. An, Y. Liu, J. Hu, H. Liu, C. Tian, S. Dai, X. Yang, H. Wang, C. W. Abney and S. Dai, AIChE J., 2017, DOI: 10.1002/aic.15699.

35 S. H. Je, O. Buyukcakir, D. Kim and A. Coskun, Chem, 2016, 1 482-493.

36 P. Li, J. A. Modica, A. J. Howarth, E. L. Vargas, P. Z. Moghadam, R. Q. Snurr, M. Mrksich, J. T. Hupp and O. K. Farha, Chem, 2016, 1, 154-169.

37 Q.-L. Zhu and Q. Xu, Chem, 2016, 1, 220-245.

38 Q. Sun, B. Aguila, G. Verma, X. Liu, Z. Dai, F. Deng, X. Meng, F.-S. Xiao and S. Ma, Chem, 2016, 1, 628-639.

39 D. Banerjee, S. K. Elsaidi, B. Aguila, B. Li, D. Kim, M. J. Schweiger, A. A. Kruger, C. J. Doonan, S. Ma and P. K. Thallapally, Chem.-Eur. J., 2016, 22, 17581-17584.

40 S. Kuecken, J. Schmidt, L. Zhi and A. Thomas, J. Mater. Chem. A, 2015, 3, 24422-24427.

41 H. A. Patel, F. Karadas, A. Canlier, J. Park, E. Deniz, Y. Jung, M. Atilhan and C. T. Yavuz, J. Mater. Chem., 2012, 22, 84318437.

42 H. A. Patel and C. T. Yavuz, Chem. Commun., 2012, 48, 99899991.

43 T. Ono, T. Sugimoto, S. Shinkai and K. Sada, Adv. Funct. Mater., 2008, 18, 3936-3940.

44 G. Marcì, G. Mele, L. Palmisano, P. Pulito and A. Sannino, Green Chem., 2006, 8, 439-444. 
45 Z. L. Fan, X. J. Qin, H. X. Sun, Z. Q. Zhu, C. j. Pei, W. D. Liang, X. M. Bao, J. An, P. Q. La and A. Li, ChemPlusChem, 2013, 78, 1282-1287.

46 X. Gui, J. Wei, K. Wang, A. Cao, H. Zhu, Y. Jia, Q. Shu and D. Wu, Adv. Mater., 2010, 22, 617-621.

47 H. B. Sonmez and F. Wudl, Macromolecules, 2005, 38, 16231626.

48 A. Li, H.-X. Sun, D.-Z. Tan, W.-J. Fan, S.-H. Wen, X.-J. Qing, G.-X. Li, S.-Y. Li and W.-Q. Deng, Energy Environ. Sci., 2011, 4, 2062-2065.

49 P. D. Mines, J. Byun, Y. Hwang, H. A. Patel, H. R. Andersen and C. T. Yavuz, J. Mater. Chem. A, 2016, 4, 632-639.

50 Z. Xue, Z. Sun, Y. Cao, Y. Chen, L. Tao, K. Li, L. Feng, Q. Fu and Y. Wei, RSC Adv., 2013, 3, 23432-23437.

51 M. M. Ayad and A. A. El-Nasr, J. Phys. Chem. C, 2010, 114, 14377-14383.

52 T. K. Mahto, A. R. Chowdhuri and S. K. Sahu, J. Appl. Polym. Sci., 2014, 131, 40840.

53 L. Wang, X. L. Wu, W. H. Xu, X. J. Huang, J. H. Liu and A. W. Xu, ACS Appl. Mater. Interfaces, 2012, 4, 2686-2692.

54 L. Zhang, Y. Liu, S. Wang, B. Liu and J. Peng, RSC Adv., 2015, 5, 99618-99626.

55 H. A. Patel, F. Karadas, J. Byun, J. Park, E. Deniz, A. Canlier, Y. Jung, M. Atilhan and C. T. Yavuz, Adv. Funct. Mater., 2013, 23, 2270-2276.

56 H. A. Patel, M. S. Yavuz and C. T. Yavuz, $R S C A d v ., 2014,4$, 24320-24323.
57 H. Ali and S. K. Muhammad, J. Environ. Sci. Technol., 2008, 1, 143-150.

58 R. Dhodapkar, N. Rao, S. Pande, T. Nandy and S. Devotta, React. Funct. Polym., 2007, 67, 540-548.

59 S. Khattri and M. Singh, Water, Air, Soil Pollut., 2000, 120, 283-294.

60 S. Khattri and M. Singh, Adsorpt. Sci. Technol., 1999, 17, 269282.

61 C. Namasivayam, M. D. Kumar, K. Selvi, R. A. Begum, T. Vanathi and R. Yamuna, Biomass Bioenergy, 2001, 21, 477-483.

62 H. Parab, M. Sudersanan, N. Shenoy, T. Pathare and B. Vaze, Clean: Soil, Air, Water, 2009, 37, 963-969.

63 Z. R. Herm, B. M. Wiers, J. A. Mason, J. M. van Baten, M. R. Hudson, P. Zajdel, C. M. Brown, N. Masciocchi, R. Krishna and J. R. Long, Science, 2013, 340, 960.

64 A. Cadiau, K. Adil, P. M. Bhatt, Y. Belmabkhout and M. Eddaoudi, Science, 2016, 353, 137.

65 H. Asfour, O. Fadali, M. Nassar and M. El-Geundi, J. Chem. Technol. Biotechnol., Chem. Technol., 1985, 35, 21-27.

66 M. S. Sajab, C. H. Chia, S. Zakaria, S. M. Jani, M. K. Ayob, K. L. Chee, P. S. Khiew and W. S. Chiu, Bioresour. Technol., 2011, 102, 7237-7243.

67 P. Monash and G. Pugazhenthi, Adsorption, 2009, 15, 390405.

68 K. Periasamy and C. Namasivayam, Ind. Eng. Chem. Res., 1994, 33, 317-320. 